\title{
Electrochemical Characterization and Determination of Phenol and Chlorophenols by Voltammetry at Single Wall Carbon Nanotube/Poly(3,4-ethylenedioxythiophene) Modified Screen Printed Carbon Electrode
}

\author{
Negussie Negash, ${ }^{1}$ Hailemichael Alemu, ${ }^{2}$ and Merid Tessema ${ }^{1}$ \\ ${ }^{1}$ Department of Chemistry, Addis Ababa University, P.O. Box 1176, Addis Ababa, Ethiopia \\ ${ }^{2}$ Department of Chemistry and Chemical Technology, National University of Lesotho, P.O. Roma 180, Roma, Lesotho \\ Correspondence should be addressed to Hailemichael Alemu; hmalemu@yahoo.com
}

Received 15 July 2015; Accepted 13 October 2015

Academic Editor: Jinbo Bai

Copyright (C) 2015 Negussie Negash et al. This is an open access article distributed under the Creative Commons Attribution License, which permits unrestricted use, distribution, and reproduction in any medium, provided the original work is properly cited.

Screen printed carbon electrode (SPCE) has been modified with single wall carbon nanotube/poly(3,4-ethylenedioxythiophene) (SWCNT/PEDOT) composites for the determination of phenol and chlorophenols (phenol, 4-chlorophenol, 2,4-dichlorophenol, and 2,4,6-trichlorophenol). The effect of the modifiers on the electrode characteristics was evaluated and the responses were optimized for the voltammetric determination of phenol and chlorophenols. The parameters affecting the responses such as $\mathrm{pH}$, scan rate, and stability were studied. The analytical performance of the SWCNT/PEDOT/SPCE using cyclic voltammetry was tested and found to be impressive. Under these conditions, the designed electrode showed a good performance for the voltammetric measurements of the phenolic compounds. The modified SPCE, when it is compared with other enzymatic and nonenzymatic sensors, showed a wider dynamic range for the detection of the phenolic compounds. The modified SPCE was used for the quantification of phenol in water samples. The results suggest that the method is quite useful for analyzing and monitoring phenols and chlorophenols.

\section{Introduction}

Screen printing technique seems to be one of the most promising approaches allowing simple, versatile, rapid, and low cost sensor/biosensor production [1]. In addition, the screen printed electrode (SPE) has enabled the production of modern sensors, which can be incorporated in portable systems, an important requirement of detection methods for the direct on-field analysis of a sample without changing of the natural environmental conditions [2]. A disposable screen printed sensor can be prepared from noble metals, such as $\mathrm{Au}$ and $\mathrm{Pt}$, but these require high firing temperatures [3]. Inks based on carbon have very low firing temperature and can be printed on plastic substrates. Therefore, the most commonly used material for SPE fabrication is carbon ink and thus named as screen printed carbon electrode (SPCE).
The applications of sensors based on screen printed electrodes for the detection of heavy metals in biomolecules, pesticides, antigens, and ions have been well documented [4-7]. Electrochemical sensors based on screen printed electrodes are simple to be used with in situ screening devices, since all the equipment needed for the electrochemical analysis is portable. They have all the basic performance characteristics of sensors, among them the requirement of minimum sample preparation, simplicity of the apparatus, fast responses, low cost, and miniaturization with new technologies $[7,8]$.

Disposable electrochemical sensors based on SPCE for the determination of trace levels of pollutants and toxic compounds in environmental and biological samples are also attractive because of economic considerations and the design of SPCE can be changed with respect to the requirements for a specific analyte. In addition, the surface of SPCE can 
be easily modified to fit multiple purposes with regard to different pollutants and to achieve a variety of improvements $[9,10]$.

Phenolic compounds usually coexist in environmental samples and are toxic to animals and aquatic organisms. Therefore, the rapid in situ determination of phenolic compounds and their derivatives is an important environmental challenge. SPCE based electrochemical sensors and biosensors have led to a low cost, simple and sensitive analytical method for the identification and determination of phenolic compounds. In fact, the electrooxidation products of phenol would passivate the surface of SPCEs and hinder the electron transfer process. To alleviate such problems, different configurations for the design of screen printed enzymatic biosensors involving different techniques for enzyme immobilization have been attempted $[6,11]$. Enzymes have been widely used in the preparation of biosensors for the analysis of phenolic compounds and have allowed the measurement to be performed at a low applied potential with significant reduction of interference. Reports of studies performed at chemically modified SPCEs for the determination of phenolic compounds include nanomaterial modified SPCE [12], a nanocomposite-modified SPCE coated with multiwalled carbon nanotubes (MWCNT), electrodeposited gold nanoparticles (AuNPs) [2], and an electrochemically pretreated SPCE [13]. Enzyme based SPCE still suffers from the rapid loss of the biochemical activity of the enzyme and leakage into the solution. An electrochemically pretreated SPCE offers simple analysis of phenolic compounds but is limited to diols which suffers less in fouling due to the electrochemical passivation of phenol oxidation products [6].

On the other hand, conducting polymers such as polyaniline, polypyrrole, and polythiophene are suitable materials as electrocatalysts for detecting organic and biological molecules [14]. Due to the continued interests in exploring the applications of polymeric layers in electroanalysis, poly $(3,4-$ ethylenedioxythiophene), PEDOT, the conducting polymer, has been used to modify SPCE. For example, the electrochemical investigation of neutral acetaminophen (ACAP) at PEDOT modified SPCE shows favorable electrocatalysis for ACAP in aqueous media [15]. Tyrosinase based biosensors with PEDOT/Poly(styrene sulphonate) modified SPCE allowed the detection of phenolic compounds with significantly improved sensitivity and wider linear range when compared to Tyrosinase immobilized on screen printed carbon electrode [16].

The incorporation of nanomaterials in the screen printed electrodes has attracted attention in the development of electrochemical sensors. Carbon nanotubes that are molecularscale tubes of graphitic carbon present a singular structure and dimensions together with unique electronic, chemical, and mechanical properties. [17-19]. As electrode materials, CNT facilitate electron transfer between the electroactive species and the electrode. Consequently, the sensors have fast response and signal enhancements. One of the carbon nanotubes is SWCNTs, which are one-dimensional conductor with all electrons moving in an atomic layer having surface atoms. Recently, a novel screen printed single wall carbon nanotube electrode cast on flexible polyester substrates was fabricated and electrochemically characterized. The electroanalytical performance of this sensor was applied towards the detection of potassium ferrocyanide(II), dopamine, hydrazine, and capsaicin [20].

At present, there is a great interest in exploiting the exciting properties of these CNTs by incorporating them into some form of polymer matrix. Indeed, a large number of preparation techniques have been attempted to form CNTs/ polymer composites with enhanced mechanical and electrical properties [21-25]. Although a number of electrode materials based on CNT-conducting polymer composite were used for the voltammetric determination of phenol and its derivatives, very few researchers investigated the use of CNT-conducting polymer composites modified SPCE electrodes [26].

The preparation of new type of composite materials that have distinct properties as modifiers of SPCE for the electrocat-alytic oxidation of phenol and chlorophenols was the aim of this study. To the best of our knowledge, the modification and application of SPCE with SWCNT/PEDOT as voltammetric sensor for phenol and chlorophenols had not been reported so far. The study thus focused on the development of screen printed carbon electrode modified with the composites of SWCNT/PEDOT for the investigation of the electrochemical behavior and determination of phenol and chlorophenols.

\section{Experimental}

2.1. Chemicals and Reagents. SWCNT (mixtures of metallic and semiconducting), 3,4-ethylenedioxythiophene (EDOT) monomer, and tetrabutylammonium perchlorate were purchased from Sigma-Aldrich (Prestige Laboratory Supplies Company, Durban, South Africa). Sodium acetate, phenol, 4chlorophenol, 2,4-dichlorophenol, and 2,4,6-trichlorophenol were purchased from Fluka (Shalom Laboratory Supplies Company, Durban, South Africa) which were used in the experiments. Other chemicals were from Chemoquip (Johannesburg, South Africa). All chemicals were of analytical grade and were used without further purification. All solutions were prepared using ultrapure water of resistivity $18.2 \mathrm{M} \Omega$ $\mathrm{cm}$ obtained from ELGA PURELAB Option-Q (UK) water purification system. SWCNT was dispersed in N,N-dimethylformamide (1 mg SWCNT:1 mL DMF) and sonicated for 1 hour to achieve well-dispersed suspension. EDOT monomer of concentration $0.01 \mathrm{M}$ was dissolved in acetonitrile that contained $0.1 \mathrm{M}$ tetrabutylammonium perchlorate supporting electrolyte. Fresh solutions of $10^{-2} \mathrm{M}$ phenol in water and $10^{-3} \mathrm{M}$ of 4-chlorophenol, 2,4-dichlorophenol, and 2,4,6-trichlorophenol were prepared separately in 50\% water/methanol mixture and diluted to the required concentrations. Sodium acetate of concentration $0.1 \mathrm{M}$ was used as a buffer solution and the required $\mathrm{pH}$ was adjusted by adding either acetic acid or sodium hydroxide solution.

2.2. Preparation of Modified Electrodes. SWCNT modified SPCE was prepared by depositing $10 \mu \mathrm{M}$ dispersion of SWCNT onto the surface of the bare electrode followed by drying it at room temperature for an overnight and is denoted as SPCE/SWCNT. PEDOT modified SPCE was prepared by 


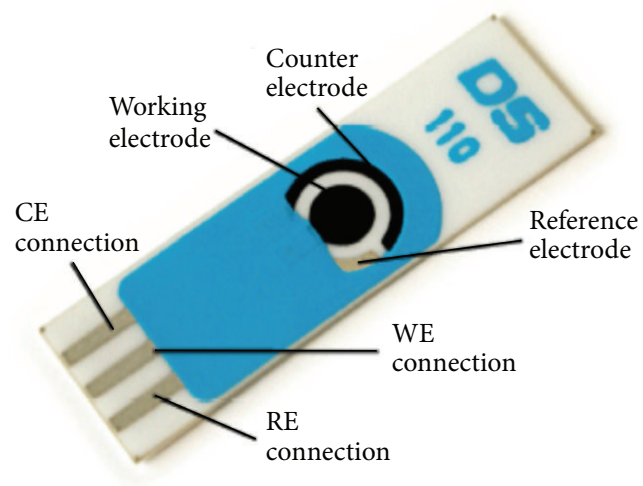

(a)

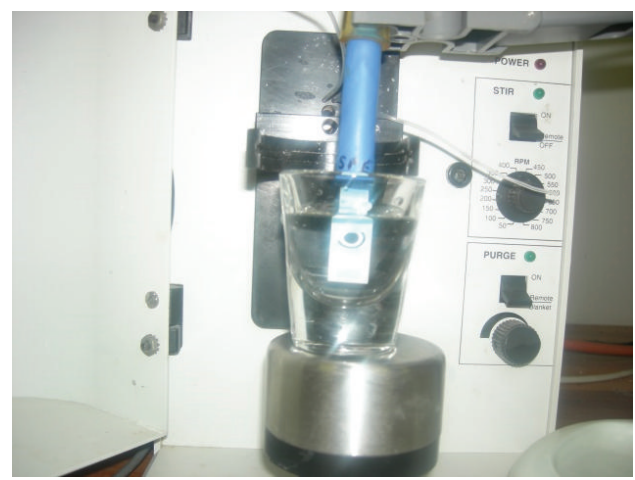

(b)

FIGURE 1: The electrochemical cell: (a) screen printed carbon electrode, counter carbon electrode, and Ag reference electrode; (b) connector cable with the electrochemical cell.

electropolymerization of $0.01 \mathrm{M}$ EDOT on the surface of SPCE. The polymer film was washed with water to remove the supporting electrolyte and the unreacted monomer. Electrochemical polymerization of EDOT on SPCE was performed by 10 cycles of cyclic voltammetry scanning the potential from -0.9 to $+1.5 \mathrm{~V}$ at a scan rate of $10 \mathrm{~V} \mathrm{~s}^{-1}$ [16]. Different PEDOT modified electrodes were prepared by varying the number of potential cycles $(5,10,20,40$, and 60$)$ to obtain films of varying thicknesses. The PEDOT modified film electrode is denoted as SPCE/PEDOT.

Further, two types of modified electrodes, namely, SPCE/ SWCNT/PEDOT and SPCE/PEDOT/SWCNT, were prepared. SPCE/SWCNT/PEDOT was prepared by coating first the SWCNT suspension on the SPCE followed by polymerization of EDOT and SPCE/PEDOT/SWCNT was prepared by polymerizing first EDOT on the SPCE and then casting the SWCNT suspension. Prior to the experimental measurements, the modified electrodes were first activated by 20 repetitive potential cycling between 0 and $1.2 \mathrm{~V}$ in $0.1 \mathrm{M}$ acetate buffer solution as the base electrolyte to obtain steady state $\mathrm{CV}$ responses at a scan rate of $50 \mathrm{mV} \mathrm{s}^{-1}$.

2.3. Instrumentation. Electrochemical measurements were carried out in a single-compartment cell using CHI 840C Work Station (USA) controlled by Dell, personal computer. A conventional three-electrode system was used in the voltammetric measurements. Disposable SPCE (DRP110) consisting of carbon ink based working electrode $(4 \mathrm{~mm}$ diameter), a carbon counter electrode, and an Ag reference electrode was purchased from DropSens Inc. (Spain) for the electrochemical measurements. The working electrode was modified to obtain SPCE/SWCNT, SPCE/PEDOT, SPCE/SWCNT/PEDOT, and SPCE/PEDOT/SWCNT. A sensor connector cable CAC (DropSens Inc., Spain) allowed for connecting the electrodes to the CHI Work Station.

The electrochemical cell volume in all experiments was $10 \mathrm{~mL}$, and all measurements were performed at room temperature. The $\mathrm{pH}$ of the solutions was measured using Jenway 3345 pH/Ion meter and for sonication Branson 2510
(USA) ultrasonic water bath was used. Figure 1 shows the screen printed carbon electrode, counter carbon electrode, Ag reference electrode, and the connector cable with the electrochemical cell.

\section{Results and Discussion}

3.1. Electrochemical Behavior of Phenol at Screen Printed Carbon Electrode and Modified Screen Printed Carbon Electrodes. Screen printed carbon electrodes (SPCEs) were modified with SWCNTs, PEDOT, and PEDOT/SWCNTs composites. SWCNTs were added to the modified electrode for the detection of phenol in order to improve its sensitivity, stability, and mechanical strength. CV was chosen in this work because it provides a better way to control the growth of the polymer film and to avoid overoxidation. Different PEDOT modified electrodes were prepared by varying the number of potential cycles: 5, 10, 20,40, and 60 to obtain films of varying thicknesses between the potential window -0.9 and $+1.5 \mathrm{~V}$. The extent of electropolymerization increased with increasing the cycle. A plot of current versus number of cycles showed that the polymer film prepared with 10 cycles had the best current response (figure not shown).

The voltammetric responses of bare screen printed and modified screen printed electrode for $10^{-4} \mathrm{M}$ phenol, in $0.1 \mathrm{M}$ acetate buffer, $\mathrm{pH} 6$, were studied using CV. Figure 2 compares cyclic voltammograms of the buffer solution and $10^{-4} \mathrm{M}$ phenol at SPCE, SPCE/SWCNTs, SPCE/PEDOT, SPCE/PEDOT/SWCNTs, and SPCE/SWCNTs/PEDOT.

In the presence of only the base electrolyte, Figure 2(a), the voltammogram of SPCE/SWCNTs/PEDOT (E) shows large background current which is an indication of the effective modification of the electrode which is exhibited by large double-layer charging current. Compared with the bare SPCE (A), the SWCNTs modified SPCE (B) and the PEDOT modified SPCE do not show significant difference in their background currents.

Figure 2(b) shows the oxidation peaks of $1 \times 10^{-4} \mathrm{M}$ phenol at the different five electrodes. The peak potentials and 


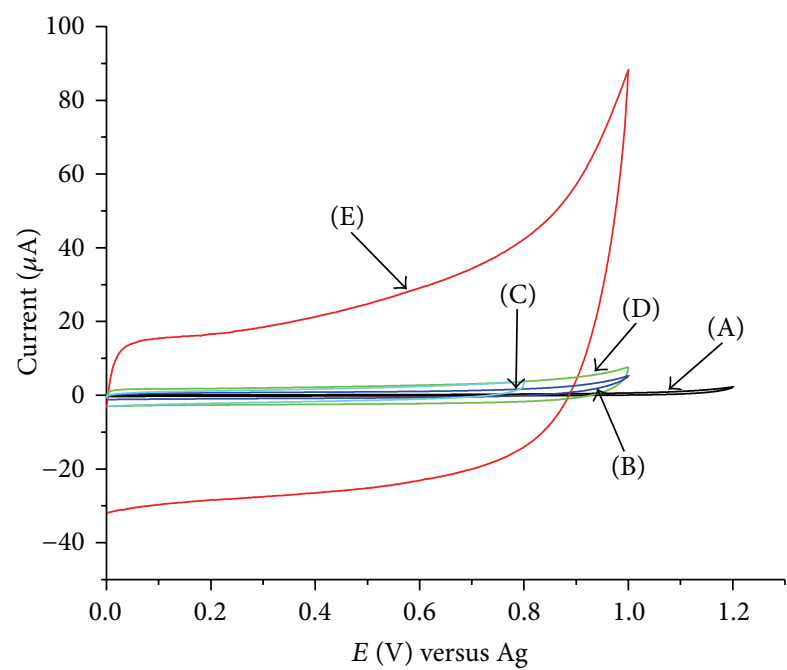

(a)

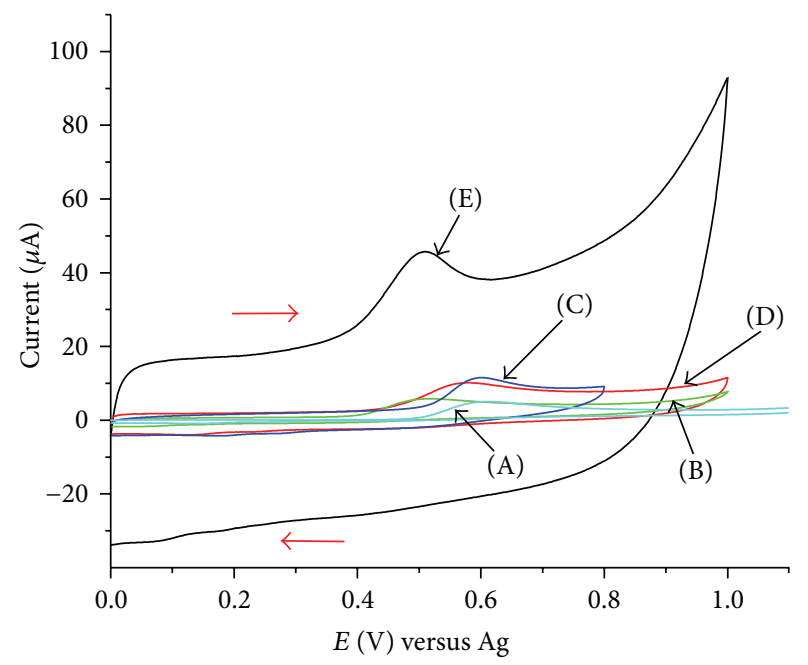

(b)

FIGURE 2: Cyclic voltammograms for the base electrolyte (a) and $1 \times 10^{-4} \mathrm{M}$ phenol (b) at SPCE (A), SPCE/SWCNTs (B), SPCE/PEDOT (C), SPCE/PEDOT/SWNTs (D), and SPCE/SWCNTs/PEDOT (E); scan rate: $0.050 \mathrm{~V} \mathrm{~s}^{-1} ; 0.1 \mathrm{M}$ acetate buffer $\mathrm{pH} 6$.

peak currents of phenol at the five electrodes are presented in Table 1. As shown in the table, the peaks of phenol appear at different potentials and the lowest peak potential is $509 \mathrm{mV}$ for the electrode SPCE/SWCNTs/PEDOT which is $48 \mathrm{mV}$ lower than the unmodified SPCE. Comparison of the peak currents of phenol at these electrodes also shows that the maximum peak current is $21.38 \mu \mathrm{A}$ corresponding to the electrode SPCE/SWCNTs/PEDOT. This value is five times larger than the value recorded for the unmodified SPCE. The SPCE/PEDOT and SPCE/PEDOT/SWCNTs also show enhancement in the peak current of phenol as twice as that of SPCE, whereas the current for SPCE/SWCNTs is not significantly different from SPCE.

The modification of the screen printed carbon electrode with SWCNTs followed by EDOT polymerization (SPCE/SWCNTs/PEDOT) shows much stronger electrocatalytic activity for the oxidation of phenol resulting in an increase of the peak current and negative shift of the peak potential. Thus, it can be concluded that the increase in peak currents and shift in peak potential are the result of the synergic effect for the incorporation of SWCNTs into the PEDOT polymer [27].

The electrocatalytic activity of the SWCNT, PEDOT, and composite film modified SPCE is demonstrated by running repetitive cyclic voltammograms for $1.0 \times 10^{-4} \mathrm{M}$ phenol in $\mathrm{pH} 6.0$ acetate buffer solution recorded at five different working electrodes. Figure 3(a) shows the repetitive ten cyclic voltammograms at the bare SPCE. The oxidation of phenol appears at $639 \mathrm{mV}$ and after the first cycle the current decreases substantially and becomes stable after the second cycle. A continuous decrease in the peak current was observed with a gradual positive shift in the peak potential at the SPCE/SWCNTs for ten successive cycles signifying a fouling of the electrode surface as a result of the formation of nonconducting oxidation product of phenol. Similar gradual positive potential shifts without much
TABLE 1: Comparative potential and current responses for $1 \times 10^{-4} \mathrm{M}$ phenol at SPCE and modified SPCE.

\begin{tabular}{lcc}
\hline Sensor & Peak potential $(\mathrm{V})$ & Peak current $(\mu \mathrm{A})$ \\
\hline SPCE & 0.639 & 4.259 \\
SPCE/SWCNTs & 0.518 & 4.801 \\
SPCE/PEDOT & 0.602 & 8.228 \\
SPCE/PEDOT/SWCNTs & 0.580 & 7.182 \\
SPCE/SWCNTs/PEDOT & 0.509 & 21.38 \\
\hline
\end{tabular}

decrease in current were observed at SPCE/PEDOT and SPCE/PEDOT/SWCNTs (figures not shown). Figure 3(b) shows the oxidation of phenol at the SPCE/SWCNTs/PEDOT for ten repetitive cyclic voltammograms. The peak potential and the peak current remain the same for all cycles indicating the absence of fouling of the electrode or change in the morphology of the surface of the electrode. The low oxidation peak potential and the enhanced peak current observed at this electrode clearly demonstrates that SPCE/SWCNTs/PEDOT composite film efficiently promotes the kinetics of the electrochemical reaction, which is probably caused by the synergistic effect of the electrocatalytic property of SWCNTs and PEDOT [27] and the contribution from the unique electronic and chemical properties of CNTs $[17,18]$. CNT modified SPCEs are mechanically strong and provide excellent attachment to the ink surfaces [2,27]. These results indicate that the SPCE/SWCNTs/PEDOT composite film modified electrode can not only detect phenol, but also enhance the detection sensitivity. Furthermore, the modified electrode was used and applied for the analysis of chlorinated phenols.

3.2. Effect of $p H$. As the solution $\mathrm{pH}$ is an important factor affecting the electrochemical reactions of phenolic compounds in aqueous solution, cyclic voltammetry was 


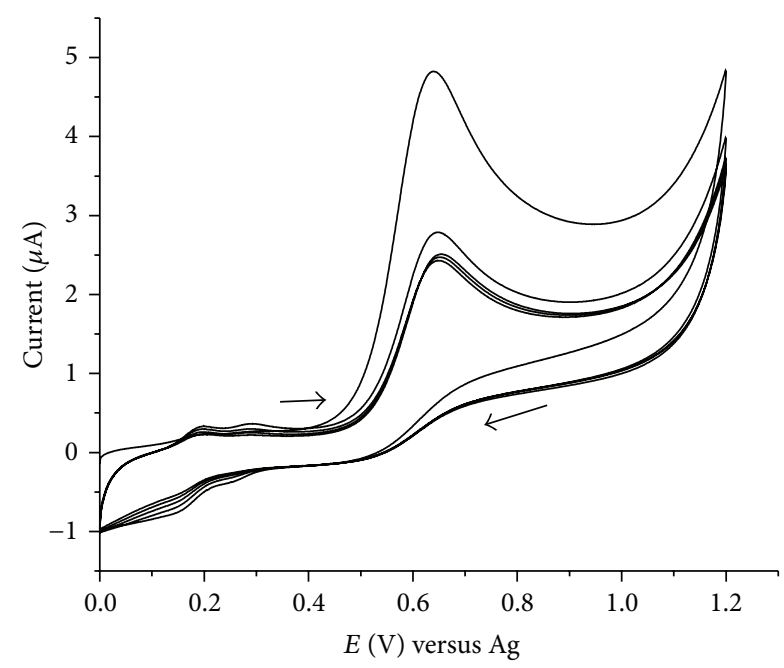

(a)

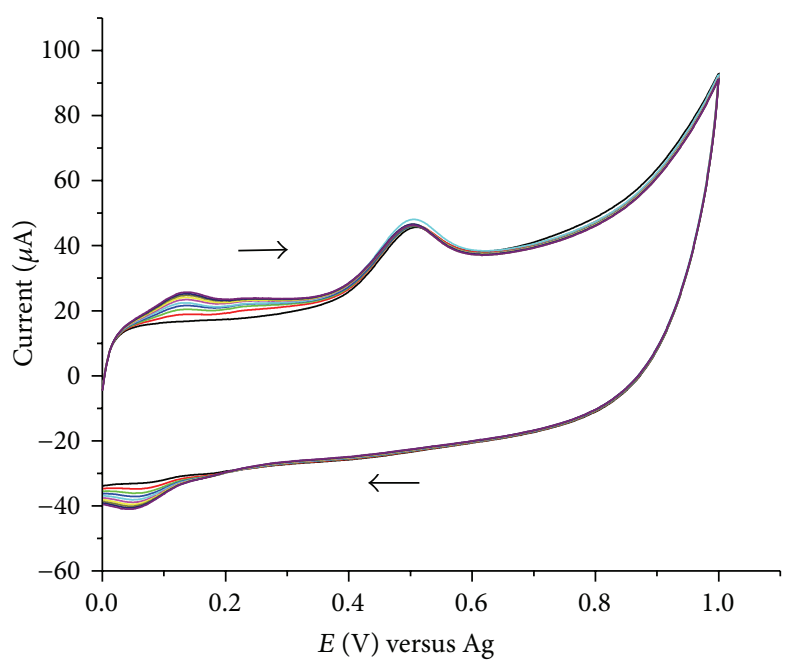

(b)

FIGURE 3: Repetitive cyclic voltammograms for $1 \times 10^{-4} \mathrm{M}$ phenol in a $0.1 \mathrm{M}$ acetate buffer solution, pH 6 at bare SPCE (a) and SPCE/SWCNTs/PEDOT (b); scan rate of $0.05 \mathrm{~V} \mathrm{~s}^{-1}$.

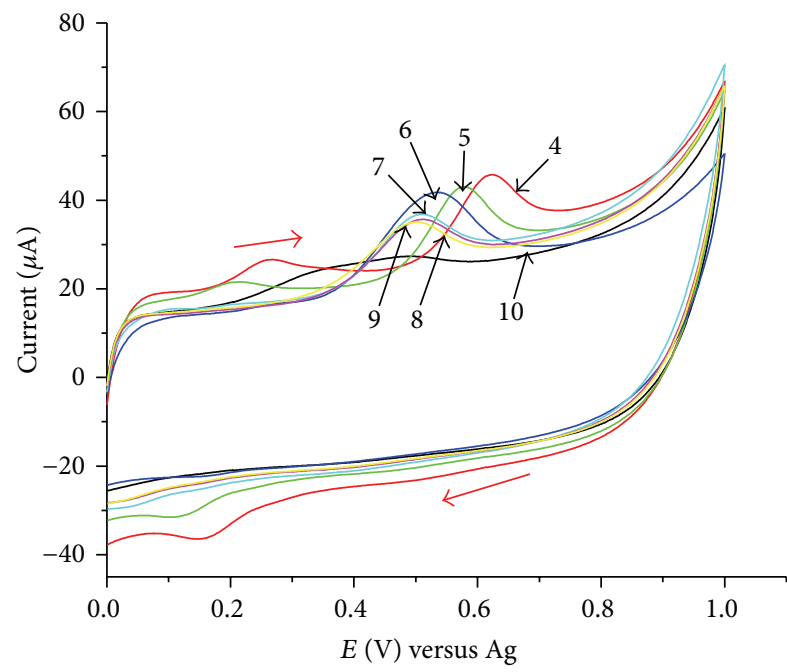

(a)

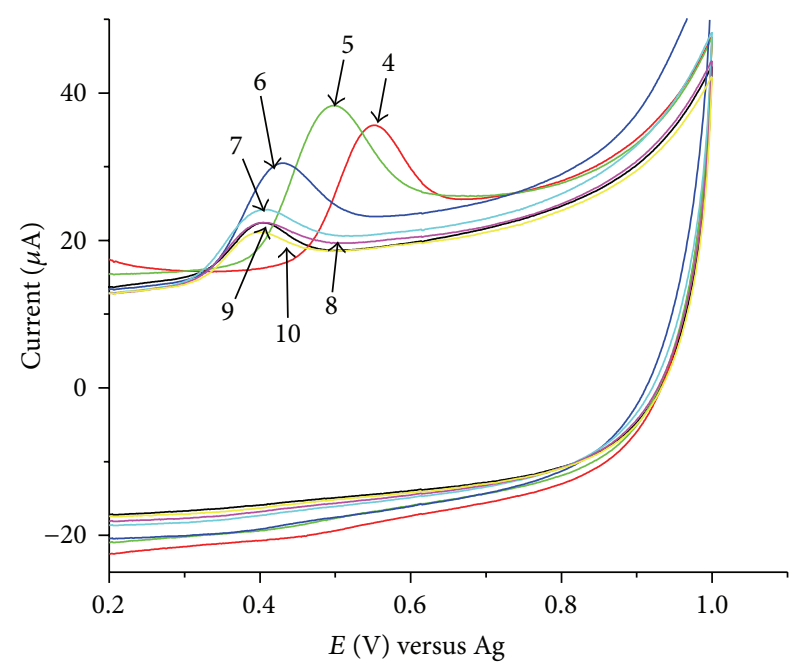

(b)

FIGURE 4: Cyclic voltammograms for $1.0 \times 10^{-4} \mathrm{M}$ phenol (a) and 2,4,6-trichlorophenol (b) at SPCE/SWCNTs/PEDOT in $0.1 \mathrm{M}$ acetate buffer solution of varying $\mathrm{pH}$; scan rate: $0.05 \mathrm{~V} \mathrm{~s}^{-1}$.

performed to investigate the effect of solution $\mathrm{pH}$ on the electrochemical response of $1 \times 10^{-4} \mathrm{M}$ phenol and chlorophenols at the SPCE/SWCNTs/PEDOT. The effect of $\mathrm{pH}$ on the anodic peak current of phenol and chlorophenols were examined in the $\mathrm{pH}$ range 4 to 10 using $0.1 \mathrm{M}$ acetate buffer and the representative figures are depicted in Figure 4 . The oxidation peak current for phenol increased up to $\mathrm{pH} 6$ and gradually decreased as the $\mathrm{pH}$ increased, Figure 4(a). The same trend was also observed for 4-chlorophenol (figure not shown). For 2,4,6-trichlorophenol, the peak current increased up to $\mathrm{pH} 5$ and then gradually decreased from pH 6 to 10, Figure 4(b). Similar current versus $\mathrm{pH}$ profile was also observed for 2, 4-dichlorophenol (figure not shown). Thus, $\mathrm{pH} 6.0$ was chosen as the optimum $\mathrm{pH}$ value for the electrochemical determination of phenol and 4-chlorophenol while $\mathrm{pH} 5$ was chosen for 2,4-dichlorophenol and 2,4,6-trichlorophenol.

The variation of the peak potential as a function of $\mathrm{pH}$ for the oxidation of phenol and chlorophenols are depicted in Figure 5. It can be observed that the peak potentials shifted negatively with the increase in the $\mathrm{pH}$ of the supporting electrolyte solution, Figure 5. Within the range of $\mathrm{pH} 3$ to 7 , the anodic peak potentials of phenol and chlorophenols varied linearly with $\mathrm{pH}$ of the solution and with shifts to more negative values.

The linear regression equation for phenol oxidation was $E_{p}(V)=-0.0599 \mathrm{pH}+1.228(R=0.9784)$. The $59 \mathrm{mV} \mathrm{pH}{ }^{-1}$ 
TABLE 2: Dependence of the peak current on the scan rate.

\begin{tabular}{lccccc}
\hline Scan rate $v\left(\mathrm{Vs}^{-1}\right)$ & $\sqrt{v}$ & $\begin{array}{c}\text { Phenol } \\
i(\mu \mathrm{A})\end{array}$ & $\begin{array}{c}\text { 4-Chlorophenol } \\
i(\mu \mathrm{A})\end{array}$ & $\begin{array}{c}\text { 2,4-Dichlorophenol } \\
i(\mu \mathrm{A})\end{array}$ & $\begin{array}{c}\text { 2,4,6-Trichlorophenol } \\
(\mu \mathrm{A})\end{array}$ \\
\hline 0.02 & 0.141 & 8.23 & 20.79 & 14.92 & 26.97 \\
0.05 & 0.224 & 13.66 & 32.59 & 38.15 & 28.79 \\
0.08 & 0.283 & 17.66 & 39.74 & 43.51 & 33.41 \\
0.10 & 0.316 & 19.13 & 41.05 & 49.90 & 38.54 \\
0.13 & 0.361 & 22.40 & 46.19 & 54.72 & 42.98 \\
0.15 & 0.387 & 23.05 & 51.06 & 57.65 & 45.99 \\
0.18 & 0.424 & 24.21 & 55.70 & 59.35 & 44.99 \\
0.20 & 0.447 & 26.23 & 58.73 & & \\
0.25 & 0.500 & 28.43 & 65.07 & & \\
0.30 & 0.548 & 30.91 & 69.05 & & \\
\hline
\end{tabular}

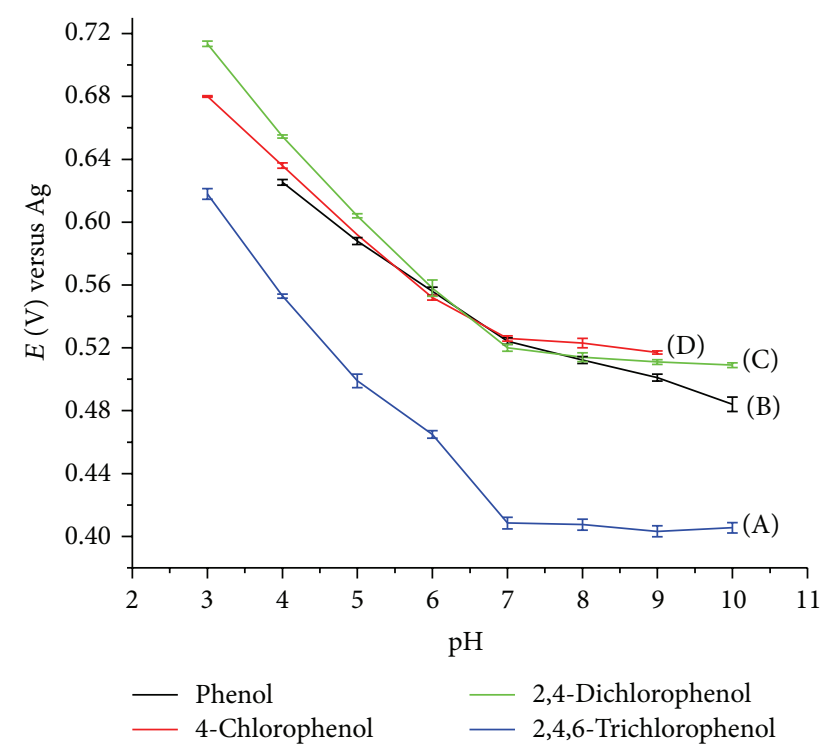

FIgUre 5: The effect of $\mathrm{pH}$ on peak potential of $1 \times 10^{-4} \mathrm{M}$ : 2,4,6-trichlorophenol (A), phenol (B), 2,4-dichlorophenol (C), and chlorophenol (D); other conditions are as in Figure 4.

slope indicated that the electrochemical oxidation of phenol was two-electron two-proton process. In view of the above findings, it is obvious that the oxidation of phenol and chlorophenols is a favorable process in acidic medium.

3.3. Effect of Scan Rate. The effect of scan rate on the cyclic voltammetric responses at SPCE/SWCNTs/PEDOT was investigated using $0.1 \mathrm{M}$ acetate buffer solutions. Figure 6 depicts the representative cyclic voltammograms obtained for $1 \times 10^{-4} \mathrm{M}$ phenol and 2,4-dichlorophenol studied at SPCE/SWCNTs/PEDOT in the scan rate range of 0.02 to $0.40 \mathrm{~V} \mathrm{~s}^{-1}$. The oxidation peak of phenol is observed in the potential range of $0.5-0.6 \mathrm{~V}$ shifting more towards positive potential with increasing scan rate. Another anodic peak is also observed at about $0.2 \mathrm{~V}$ that that has a corresponding reduction peak at about $0.1 \mathrm{~V}$. The electrooxidation pathway of phenol at a modified electrode is different from that of unmodified electrode [24, 28]. At modified electrode, the oxidation peak of phenol is followed by the formation of paraquinone/hydroquinone redox couple and or orthoquinone/catechol redox couple. The redox peaks that are observed in the potential region of $0.1-0.2 \mathrm{~V}$ presumably could be due to the formation of ortho-quinone/catechol. Table 2 summarizes the oxidation peak currents of phenol and chlorophenols at different scan rates. A plot of the oxidation peak currents as a function of the square root of the scan rate is shown in Figure 7. From the plots of the peak current versus the square root of the scan rate $\left(v^{1 / 2}\right)$, it was found that the peak current is proportional to the square root of the scan rate in the range of 0.02 to $0.35 \mathrm{~V} \mathrm{~s}^{-1}$ for phenol and chlorophenol and in the range of 0.02 to $0.25 \mathrm{~V} \mathrm{~s}^{-1}$ for 2,4-dichlorophenol and 2,4,6-trichlorophenol with an average of 0.998 regression coefficient. At relatively higher scan rate for 2,4-dichlorophenol and 2,4,6-trichlorophenol distortion of the $\mathrm{CV}$, waves were observed. This effect often sets the limits of maximum useful scan rate and the charging current becomes relatively more important at faster scan rates [29]. The linear dependence of the oxidation peak currents on the square root of the scan rate indicates that the electrochemical reactions are diffusion controlled processes, similar to previous studies of the electrochemical oxidation of phenol and chlorophenols $[13,15,30]$.

3.4. Electroanalytical Applications of the SPCE/SWCNTS/ PEDOT Sensor. The current responses of SPCE/SWCNTs/ PEDOT for the concentration of phenol, 4-chlorophenol, 2,4-dichlorophenol, and 2,4,6-trichlorophenol were studied using linear scan anodic voltammetry measurements at the optimized conditions. Increase in the current responses was observed as the concentrations of phenol and chlorophenols were increased. All phenols and chlorophenols gave two linear ranges when the oxidation current responses were plotted as a function of their concentrations. Figure 8, for example, depicts the linear scan anodic voltammograms for phenol (a) and $\left(\mathrm{a}^{\prime}\right)$ for the concentration ranges $0.6-100 \mu \mathrm{M}$ and $200-600 \mu \mathrm{M}$, respectively, and for 2,4,6-trichlorophenol (b) and $\left(\mathrm{b}^{\prime}\right)$ for the concentration ranges $0.4-100 \mu \mathrm{M}$ and 


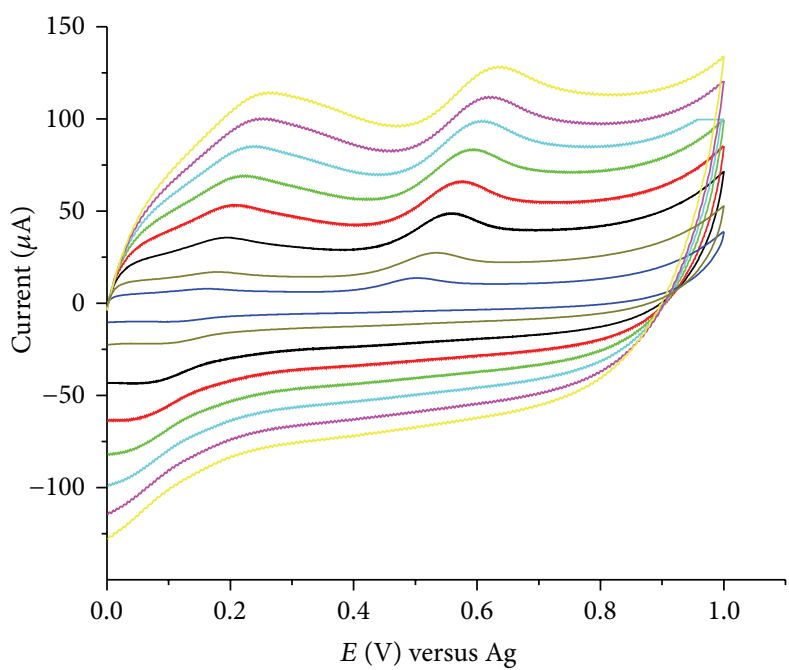

(a)

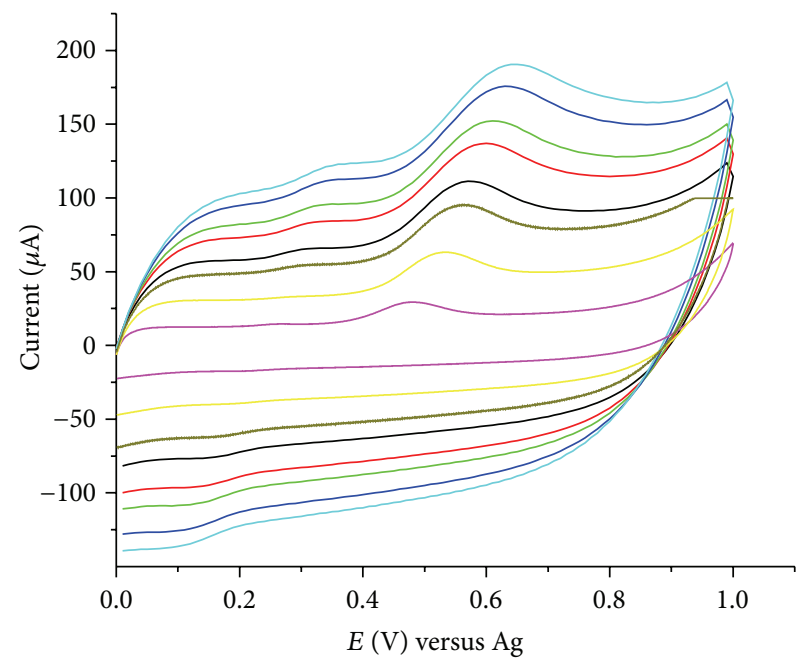

(b)

Figure 6: Cyclic voltammograms for $1 \times 10^{-4} \mathrm{M}$ phenol (a) and 2,4-dichlorophenol (b). For phenol, scan rate: 0.02, 0.05, 0.10, 0.15, 0.20, 0.25, and $0.30 \mathrm{~V} \mathrm{~s}^{-1}, \mathrm{pH}$ 6; for 2,4-dichlorophenol, scan rat: $0.02,0.05,0.08,0.1,0.13,0.15,0.18$, and $0.20 \mathrm{~V} \mathrm{~s}^{-1}$, pH 5.

TABLE 3: Response characteristics of the calibration graphs for the different phenolic compounds at SPCE/SWCNTs/PEDOT electrochemical sensor.

\begin{tabular}{|c|c|c|c|c|c|}
\hline \multirow{2}{*}{ Phenolic compound } & \multicolumn{2}{|c|}{$i(\mu \mathrm{A})=a c(\mu \mathrm{M})+b$} & \multirow{2}{*}{ Linear range $(\mu \mathrm{M})$} & \multirow{2}{*}{ Detection limit $(\mu \mathrm{M})$} & \multirow{2}{*}{$R^{2}$} \\
\hline & Slope $(a)$ & Intercept $(b)$ & & & \\
\hline \multirow{2}{*}{ Phenol } & 0.196 & 0.389 & $0.6-100$ & \multirow{2}{*}{0.38} & 0.999 \\
\hline & 0.046 & 1.699 & $200-600$ & & 0.996 \\
\hline \multirow{2}{*}{ 4-Chlorophenol } & 0.339 & 1.283 & $0.8-100$ & \multirow{2}{*}{0.28} & 0.996 \\
\hline & 0.054 & 36.920 & $200-500$ & & 0.998 \\
\hline \multirow{2}{*}{ 2,4-Dichlorophenol } & 0.341 & 1.681 & $0.5-60$ & \multirow{2}{*}{0.16} & 0.998 \\
\hline & 0.156 & 11.804 & $50-300$ & & 0.998 \\
\hline \multirow{2}{*}{ 2,4,6-Trichlorophenol } & 0.311 & 1.668 & $0.4-100$ & \multirow{2}{*}{0.16} & 0.998 \\
\hline & 0.148 & 5.378 & $220-500$ & & 0.990 \\
\hline
\end{tabular}

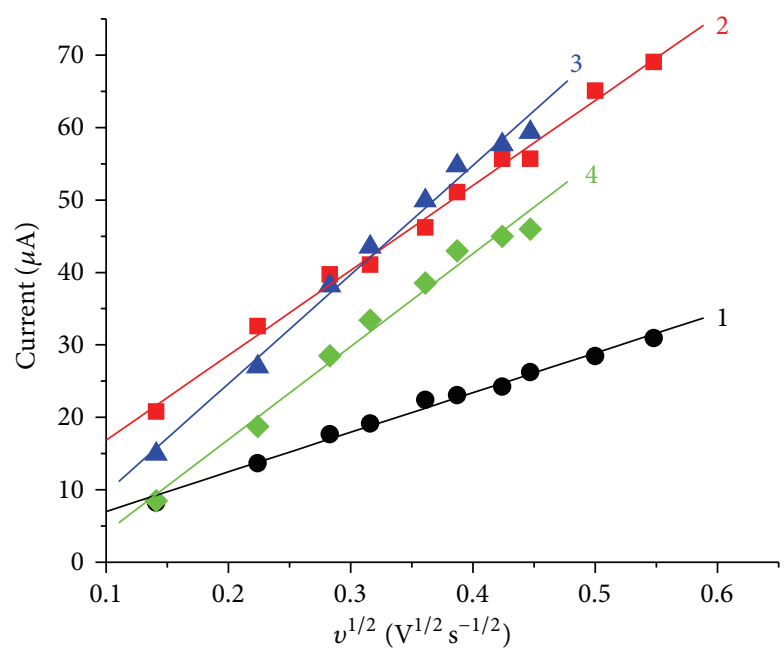

Figure 7: Plot of oxidation peak current as a function of the square root of the scan rate: phenol (1), chlorophenol (2), 2,4-dichlorophenol (3), and 2,4,6-trichlorophenol (4) each with a concentration of $1 \times 10^{-4} \mathrm{M}$.
220-500 $\mu \mathrm{M}$, respectively. The calibration curves obtained from the voltammograms (inset curves), Figure 8, show the linear relationships between the current $(\mu \mathrm{A})$ as a function of the concentrations $(\mu \mathrm{M})$ of phenol and 2,4,6trichlorophenol. Analytical parameters obtained from the response of the linear range of the calibration curves at the SPCE/SWCNTs/PEDOT electrochemical sensor are summarized in Table 3.

The analytical performance of the SPCE/SWCNTs/ PEDOT evaluated from the voltammetric responses has been compared with other screen printed electrochemical sensors reported recently, Table 4 . Characteristics such as type of electrode, linear range, sensitivity, and limit of detection achieved were compared. The PEDOT/SWCNTs composite based screen printed carbon electrode exhibits a higher electrochemical activity compared with other screen printed electrodes. In addition to the simplicity of the preparation of the sensor wider or similar dynamic ranges, low detection limits and comparable sensitivity were obtained compared to the recently reported sensors/biosensors. 


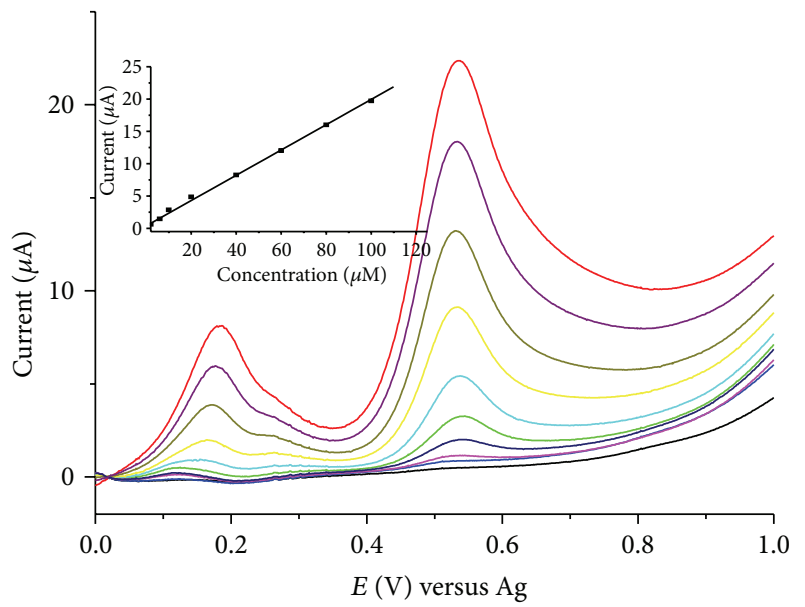

(a)

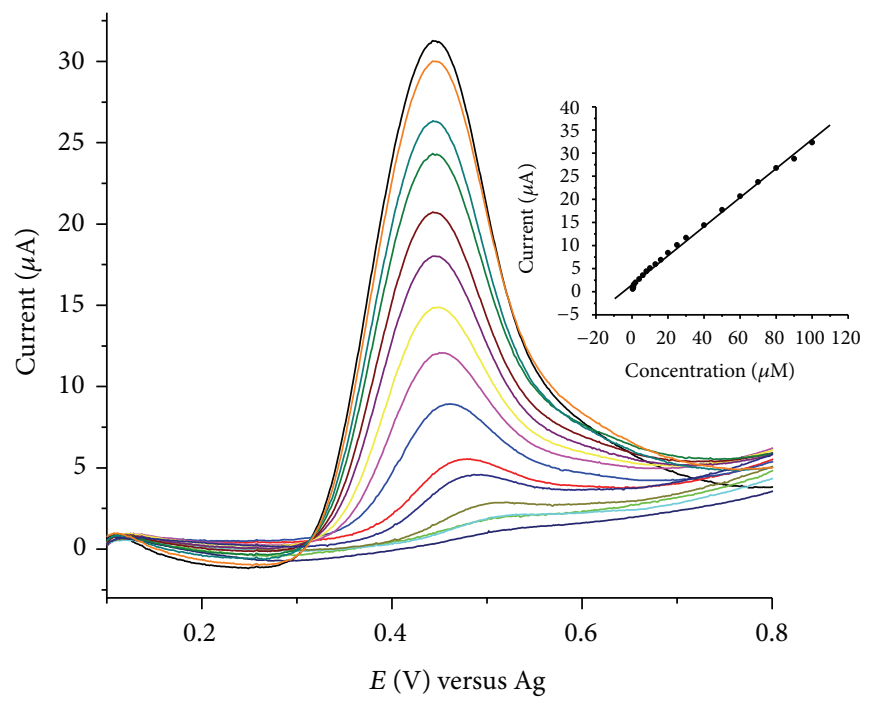

(b)

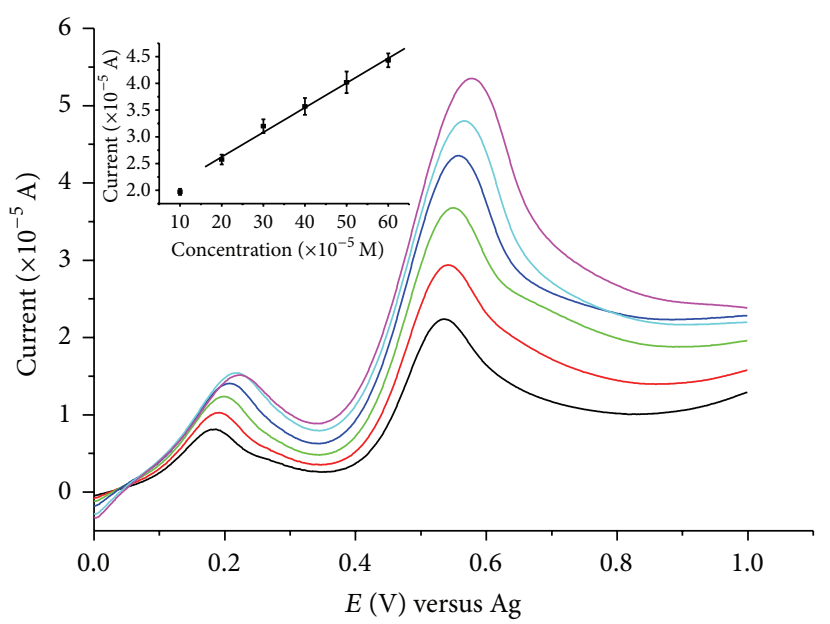

$\left(a^{\prime}\right)$

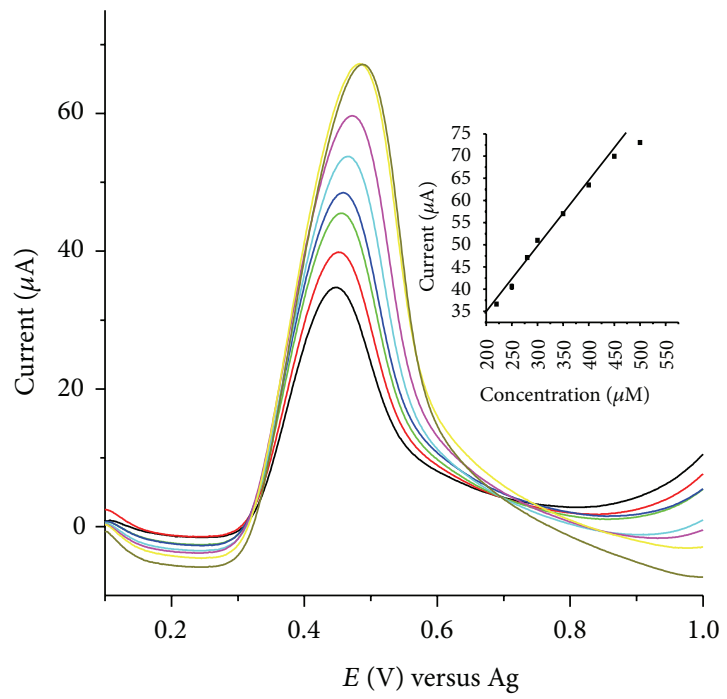

$\left(\mathrm{b}^{\prime}\right)$

FIGURE 8: Linear scan anodic voltammograms at SPCE/SWCNTs/PEDOT: for phenol (a) and ( $\mathrm{a}^{\prime}$ ) (at pH 6, concentration range: 0.6-100 $\mu \mathrm{M}$ and 200-600 $\mu \mathrm{M}$, resp.) and for 2,4,6-trichlorophenol (b) and ( $\mathrm{b}^{\prime}$ ) (at pH 5, concentration range: $0.4-100 \mu \mathrm{M}$ and 220-500 $\mu \mathrm{M}$, resp.); scan rate $0.05 \mathrm{~V} \mathrm{~s}^{-1}$. The insets are the corresponding calibration plots.

3.5. Recovery Study. The modified sensors prepared were found to be useful in the voltammetric determination of phenol in distilled and tap water. Recovery studies were carried out using three water samples each with a concentration of $0.1 \mathrm{M}$ acetate and $10 \mu \mathrm{M}$ phenol solution and three tap water samples each with a concentration of $0.1 \mathrm{M}$ acetate and $10 \mu \mathrm{M}$ phenol solution. Different concentrations of phenol were then spiked to each sample solution and the corresponding current responses were recorded. From the calibration curve for phenol $(0.6-600 \mu \mathrm{M})$, the total concentration of phenol in each sample was found as shown in Table 5. To evaluate the validity of the results, recovery values were calculated from the percentage ratio of found phenol concentration to the total phenol concentration and the values are found in the range of $98.85 \%$ to $104.46 \%$, which is in the acceptable range. The results obtained confirm that the designed modified electrode can successfully be used for the quantitative determinations of phenols and chlorophenols using voltammetry.

3.6. Reproducibility Study. The reproducibility of the results was examined by successive ten CV runs of $1 \times 10^{-4} \mathrm{M}$ phenol and chlorophenols using the optimum conditions given previously. The relative standard deviation (RSD) was calculated and it was found to be $0.65 \%$ for phenol, $0.817 \%$ for 4-chlorophenol, $2 \%$ for 2,4-dichlorophenol, and $1.12 \%$. The obtained results indicate the good stability of modified electrode.

3.7. Interference Study. Some phenolic compounds, such as 4chlorophenol (CP) and 2,4-dichlorophenol (DCP), that coexist with phenol in environmental samples can interfere in the 
TABLE 4: Comparison of different electrodes for electrochemical detections of phenol and chlorophenols.

\begin{tabular}{|c|c|c|c|c|c|}
\hline Phenolic substrate & Detector & Linear range $(\mu \mathrm{M})$ & Sensitivity $(\mu \mathrm{A} / \mu \mathrm{M})$ & Detection limit $(\mu \mathrm{M})$ & Reference \\
\hline \multirow{6}{*}{ Phenol } & $\begin{array}{l}\alpha \text {-Cyclodextrin }(\mathrm{CD}) \text { modified } \\
\text { screen printed graphite-based } \\
\text { ink }\end{array}$ & $5-100$ & 2.11 & 4.6 & {$[3]$} \\
\hline & $\begin{array}{l}\text { SPE/enzyme/immobilization } \\
\text { ATChCl } / \mathrm{H}_{2} \mathrm{O}_{2} / \text { phenol }\end{array}$ & $5-200$ & na & 3.7 & {$[31]$} \\
\hline & $\begin{array}{l}\text { Tyrosinase modified screen } \\
\text { printed four-channel } \\
\text { graphite-coated } \mathrm{Au} \text {-array }\end{array}$ & $2-40$ & 0.93 & & {$[32]$} \\
\hline & $\begin{array}{l}\text { HRP-modified screen printed } \\
\text { four-channel graphite-coated } \\
\text { Au-array }\end{array}$ & $2-300$ & 0.50 & & {$[32]$} \\
\hline & SPE/MWCNT/Bi/Tissue & $2-200$ & & 1.17 & {$[33]$} \\
\hline & SPCE/SWCNTs/PEDOT & $0.6-600$ & 0.196 & 0.38 & This work \\
\hline \multirow{3}{*}{ 4-Chlorophenol } & $\begin{array}{l}\text { Tyrosinase modified screen } \\
\text { printed four-channel } \\
\text { graphite-coated Au-array }\end{array}$ & $5-30$ & 1.610 & & {$[32]$} \\
\hline & $\begin{array}{l}\text { HRP-modified screen printed } \\
\text { four-channel graphite-coated } \\
\text { Au-array }\end{array}$ & $5-60$ & 3.380 & & {$[32]$} \\
\hline & SPCE/SWCNTs/PEDOT & $0.8-500$ & 0.339 & 0.28 & This work \\
\hline 2,4-Dichlorophenol & SPCE/SWCNTs/PEDOT & $0.5-300$ & 0.341 & 0.16 & This work \\
\hline \multirow[t]{2}{*}{ 2,4,6-Trichlorophenol } & $\begin{array}{l}\text { HRP-modified screen printed } \\
\text { four-channel graphite-coated } \\
\text { Au-array }\end{array}$ & $2-140$ & 0.21 & & {$[32]$} \\
\hline & SPCE/SWCNTs/PEDOT & $0.5-300$ & 0.311 & 0.16 & This work \\
\hline
\end{tabular}

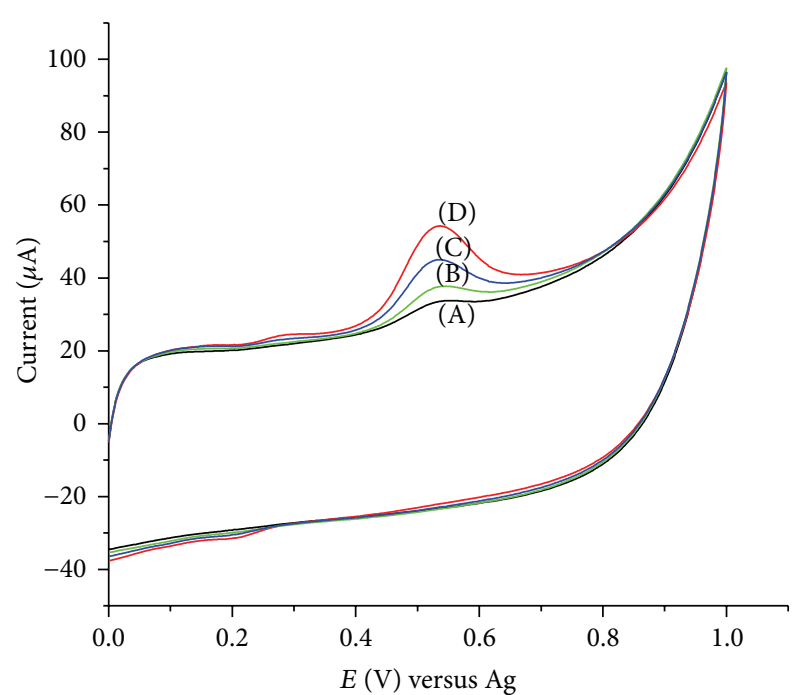

(a)

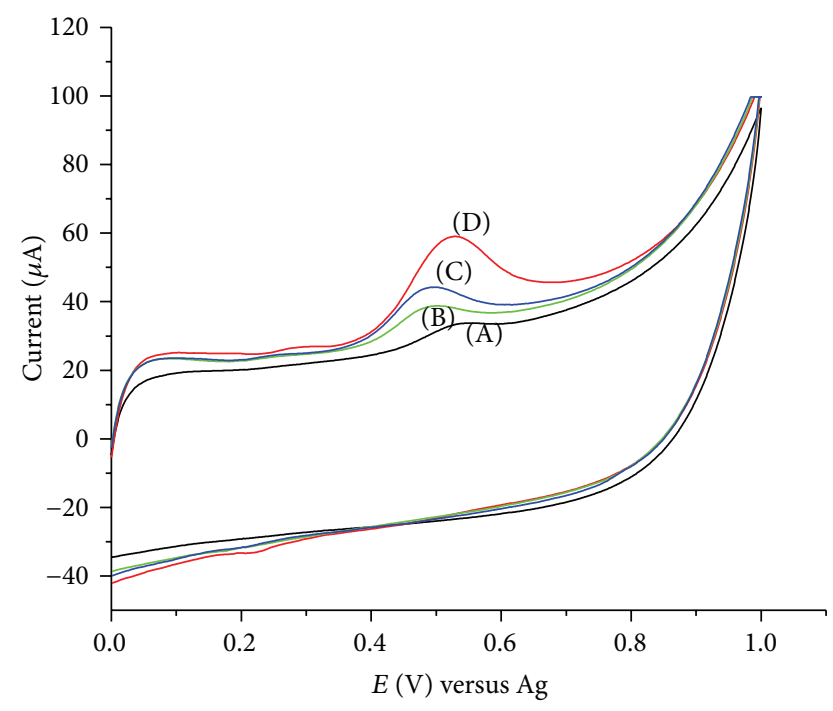

(b)

FIGURE 9: Effect of concentrations of 4-chlorophenol (a) and 2,4-dichlorophenol (b) on the response of $2 \times 10^{-5} \mathrm{M}$ phenol at pH 6; phenol (A), $1: 1(\mathrm{~B}), 1: 2(\mathrm{C})$, and $1: 5$ (D) mixtures; scan rate: $0.05 \mathrm{~V} \mathrm{~s}^{-1}$.

determination of phenols at SWCNTs/SWCNTs/PEDOT. In $\mathrm{pH} 6$ buffer solution, the oxidation peak potential of phenol was $0.551 \mathrm{~V}$ and its peak current was $6.87 \mu \mathrm{A}$. In the presence of one-to-one mixtures of CP and DCP, the peak potentials recorded were 0.546 and $0.502 \mathrm{~V}$, respectively, while the peak currents were 11.13 and $11.28 \mu \mathrm{A}$, respectively. The peak current was almost double compared to phenol alone, Figure 9. Further studies showed that the peak potentials of 2,4,6trichlorophenol (TCP) and pentachlorophenol (PC) were 0.48 and 0.614 , respectively, and the peak currents observed 
TABLE 5: Recovery study.

\begin{tabular}{lcccc}
\hline & Sample containing phenol $(\mu \mathrm{M})$ & Added phenol $(\mu \mathrm{M})$ & Found phenol $(\mu \mathrm{M})$ & Recoveries $(\%)$ \\
\hline \multirow{3}{*}{ Distilled water } & 10 & 30 & 40.75 & 70.04 \\
& 10 & 60 & 80.85 & 101.88 \\
& 10 & 70 & 39.54 & 100.06 \\
\multirow{3}{*}{ Tap water } & 10 & 30 & 61.43 & 98.85 \\
& 10 & 50 & 83.57 & 102.38 \\
\hline
\end{tabular}

for one-to-one mixture were almost the same, but the current increases and the peak gets broad as the ratio increases. The presence of $p$-nitrophenol and $o$-nitrophenol has no effect on a one-to-one mixture, but the peak current decreases as concentration ratio increases. Thus, $p$-nitrophenol and $o$ nitrophenol interfere in the determination of phenol only when present in concentrations much higher than phenol. The decrease in current response also indicates that the electrode cannot be applied for the detection of nitrophenols. The peak potentials for catechol and hydroquinone were less than $0.1 \mathrm{~V}$ and they showed no effect on the response for phenol. These results suggest that voltammetric determination of phenol in environmental samples is free of interference from catechol and hydroquinone; however, it may suffer from that of 4-chlorophenol and 2,4-dichlorophenol with higher concentrations of the other phenolic compounds.

\section{Conclusions}

SWCNTs were successfully incorporated in PEDOT and were used to modify bare SPCEs. The electrochemical oxidation of phenol, 4-chlorophenol, 2,4-dichlorophenol, and 2,4,6-trichlorophenol was successfully investigated at PEDOT/SWCNTs modified SPCE. The electrode demonstrated enhanced electron transfer properties and rapid response to phenol, and chlorophenols with good sensitivity. The well-known electrocatalytic properties of SWCNTs together with the good conductivity of PEDOT enhanced the sensing ability of SPCE. The study of the oxidation of the phenolic compounds presents an important finding in the preparation of SWCNTs/PEDOT modified SPCE sensor for the determination of phenolic compounds. The modified electrode was electrochemically characterized, optimized, and utilized for the determination of phenols and chlorophenols. The composites of electropolymerized polymers with CNTs used as modifiers significantly increased the electroactive surface area of the prepared electrode as indicated by the CV characterization steps.

The sensors developed were simple and efficient and possess a good operational stability and reproducibility. The analytical performance of the sensors made the quantification of phenolic compounds in water samples possible. Although the sensors cannot differentiate between the various phenolics present in the water samples analyzed, due to the recognition of similar functional group, they have the potential for assessing the phenolic statuses of water or other phenolic compound containing samples. However, further work is required in terms of improving the selectivity of the sensor, introduction of prior separations techniques, and the analytical applications of these sensors for the analysis of polyphenols in different samples.

\section{Conflict of Interests}

The authors declare that there is no conflict of interests regarding the publication of this paper.

\section{References}

[1] S. Ledru, N. Ruillé, and M. Boujtita, "One-step screen-printed electrode modified in its bulk with HRP based on direct electron transfer for hydrogen peroxide detection in flow injection mode," Biosensors and Bioelectronics, vol. 21, no. 8, pp. 1591-1598, 2006.

[2] D.-W. Li, Y.-T. Li, W. Song, and Y.-T. Long, "Simultaneous determination of dihydroxybenzene isomers using disposable screen-printed electrode modified by multiwalled carbon nanotubes and gold nanoparticles," Analytical Methods, vol. 2, no. 7, pp. 837-843, 2010.

[3] W.-J. Kim, S.-C. Chang, and Y.-B. Shim, " $\alpha$-cyclodextrin modified screen printed graphite electrodes for detection of phenols," Bulletin of the Korean Chemical Society, vol. 23, no. 3, pp. 427431, 2002.

[4] E. Khaled, H. N. A. Hassan, I. H. I. Habib, and R. Metelka, "Chitosan modified screen-printed carbon electrode for sensitive analysis of heavy metals," International Journal of Electrochemical Science, vol. 5, no. 2, pp. 158-167, 2010.

[5] L. K. Fatt, K. Chuenrangsikul, P. Rijiravanich, W. Surareungchai, and C. Y. Yean, "Preparation and performance test of a simplified screen-printed carbon electrode for use as a chronoamperometric transducer in genosensor," Chiang Mai Journal of Science, vol. 39, no. 4, pp. 610-622, 2012.

[6] M. Li, Y.-T. Li, D.-W. Li, and Y.-T. Long, "Recent developments and applications of screen-printed electrodes in environmental assays-a review," Analytica Chimica Acta, vol. 734, pp. 31-44, 2012 .

[7] M. Moyo, J. O. Okonkwo, and N. M. Agyei, "Recent advances in polymeric materials used as electron mediators and immobilizing matrices in developing enzyme electrodes," Sensors, vol. 12, no. 1, pp. 923-953, 2012.

[8] G. A. M. Mersal, "Electrochemical sensor for voltammetric determination of catechol based on screen printed graphite electrode," International Journal of Electrochemical Science, vol. 4, no. 8, pp. 1167-1177, 2009.

[9] M. Karim and H. J. Lee, "Amperometric phenol biosensor based on covalent immobilization of tyrosinase on Au nanoparticle modified screen printed carbon electrodes," Talanta, vol. 116, pp. 991-996, 2013. 
[10] R. O. Kadara, N. Jenkinson, and C. E. Banks, "Characterization and fabrication of disposable screen printed microelectrodes," Electrochemistry Communications, vol. 11, no. 7, pp. 1377-1380, 2009.

[11] M. Albareda-Sirvent, A. Merkoçi, and S. Alegret, "Configurations used in the design of screen-printed enzymatic biosensors. A review," Sensors and Actuators, B: Chemical, vol. 69, no. 1, pp. 153-163, 2000.

[12] J. Wang, "Nanomaterial-based electrochemical biosensors," Analyst, vol. 130, no. 4, pp. 421-426, 2005.

[13] W.-Y. Su, S.-M. Wang, and S.-H. Cheng, "Electrochemically pretreated screen-printed carbon electrodes for the simultaneous determination of aminophenol isomers," Journal of Electroanalytical Chemistry, vol. 651, no. 2, pp. 166-172, 2011.

[14] A. E. Böyükbayram, S. Kiralp, L. Toppare, and Y. Yağci, "Preparation of biosensors by immobilization of polyphenol oxidase in conducting copolymers and their use in determination of phenolic compounds in red wine," Bioelectrochemistry, vol. 69, no. 2, pp. 164-171, 2006.

[15] W.-Y. Su and S.-H. Cheng, "Electrochemical oxidation and sensitive determination of acetaminophen in pharmaceuticals at Poly(3,4-ethylenedioxythiophene)-modified screen-printed electrodes," Electroanalysis, vol. 22, no. 6, pp. 707-714, 2010.

[16] E. Moczko, G. Istamboulie, C. Calas-Blanchard, R. Rouillon, and T. Noguer, "Biosensor employing screen-printed PEDOT:PSS for sensitive detection of phenolic compounds in water," Journal of Polymer Science, Part A: Polymer Chemistry, vol. 50, no. 11, pp. 2286-2292, 2012.

[17] C. $\mathrm{Hu}$ and S. Hu, "Carbon nanotube-based electrochemical sensors: principles and applications in biomedical systems," Journal of Sensors, vol. 2009, Article ID 187615, 40 pages, 2009.

[18] C. B. Jacobs, M. J. Peairs, and B. J. Venton, "Review: carbon nanotube based electrochemical sensors for biomolecules," Analytica Chimica Acta, vol. 662, no. 2, pp. 105-127, 2010.

[19] S. K. Vashist, D. Zheng, K. Al-Rubeaan, J. H. T. Luong, and F.S. Sheu, "Advances in carbon nanotube based electrochemical sensors for bioanalytical applications," Biotechnology Advances, vol. 29, no. 2, pp. 169-188, 2011.

[20] J. P. Metters, M. Gomez-Mingot, J. Iniesta, R. O. Kadara, and C. E. Banks, "The fabrication of novel screen printed singlewalled carbon nanotube electrodes: electroanalytical applications," Sensors and Actuators B: Chemical, vol. 177, pp. 10431052, 2013.

[21] N. G. Sahoo, S. Rana, J. W. Cho, L. Li, and S. H. Chan, "Polymer nanocomposites based on functionalized carbon nanotbes," Progress in Polymer Science, vol. 35, no. 7, pp. 837-867, 2010.

[22] Z. Spitalsky, D. Tasis, K. Papagelis, and C. Galiotis, "Carbon nanotube-polymer composites: chemistry, processing, mechanical and electrical properties," Progress in Polymer Science, vol. 35, no. 3, pp. 357-401, 2010.

[23] R. Goyal and S. Bishnoi, "Surface modification in electroanalysis: past, present and future," Indian Journal of Chemistry Section A, vol. 51, pp. 205-225, 2012.

[24] N. Negash, H. Alemu, and M. Tessema, "Flow injection amperometric determination of phenol and chlorophenols at single wall carbon nanotubes modified glassy carbon electrode," American Journal of Analytical Chemistry, vol. 5, no. 3, pp. 188198, 2014.

[25] N. Negash, H. Alemu, and M. Tessema, "Determination of phenol and chlorophenols at single-wall carbon nanotubes/poly(3,4-ethylenedioxythiophene) modified glassy carbon electrode using flow injection amperometry," ISRN Analytical Chemistry, vol. 2014, Article ID 926213, 10 pages, 2014.

[26] M. Li, Y.-T. Li, D.-W. Li, and Y.-T. Long, "Recent developments and applications of screen-printed electrodes in environmental assays: a review," Analytica Chimica Acta, vol. 734, pp. 31-44, 2012.

[27] D.-M. Zhao, X.-H. Zhang, L.-J. Feng, L. Jia, and S.-F. Wang, "Simultaneous determination of hydroquinone and catechol at PASA/MWNTs composite film modified glassy carbon electrode," Colloids and Surfaces B: Biointerfaces, vol. 74, no. 1, pp. 317-321, 2009.

[28] T. A. Enache and A. M. Oliveira-Brett, "Phenol and parasubstituted phenols electrochemical oxidation pathways," Journal of Electroanalytical Chemistry, vol. 655, no. 1, pp. 9-16, 2011.

[29] A. Bard and L. Faulkner, Electrochemical Methods: Fundamentals and Applications, Wiley, New York, NY, USA, 2001.

[30] A. Remes, A. Pop, F. Manea, A. Baciu, S. J. Picken, and J. Schoonman, "Electrochemical determination of pentachlorophenol in water on a multi-wall carbon nanotubes-epoxy composite electrode," Sensors, vol. 12, no. 6, pp. 7033-7046, 2012.

[31] R. Solna, S. Sapelnikova, P. Skládal et al., "Multienzyme electrochemical array sensor for determination of phenols and pesticides," Talanta, vol. 65, no. 2, pp. 349-357, 2005.

[32] S. Sapelnikova, E. Dock, R. Solná, P. Skládal, T. Ruzgas, and J. Emnéus, "Screen-printed multienzyme arrays for use in amperometric batch and flow systems," Analytical and Bioanalytical Chemistry, vol. 376, no. 7, pp. 1098-1103, 2003.

[33] A. Merkoçi, U. Anik, S. Çevik, M. Çubukçu, and M. Guixa, "Bismuth film combined with screen-printed electrode as biosensing platform for phenol detection," Electroanalysis, vol. 22, no. 13, pp. 1429-1436, 2010. 

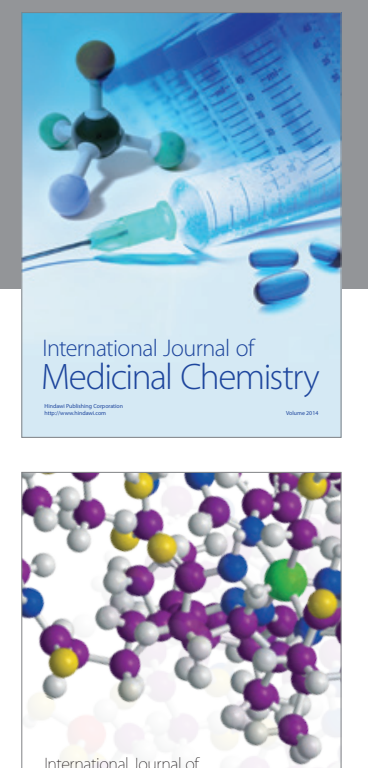

\section{Carbohydrate} Chemistry

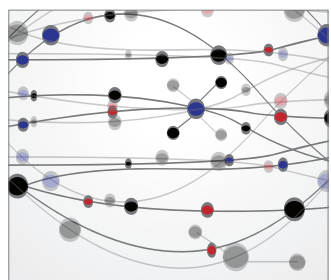

The Scientific World Journal
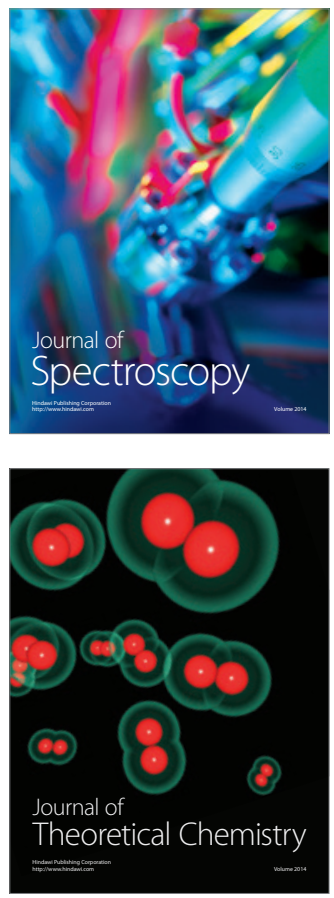
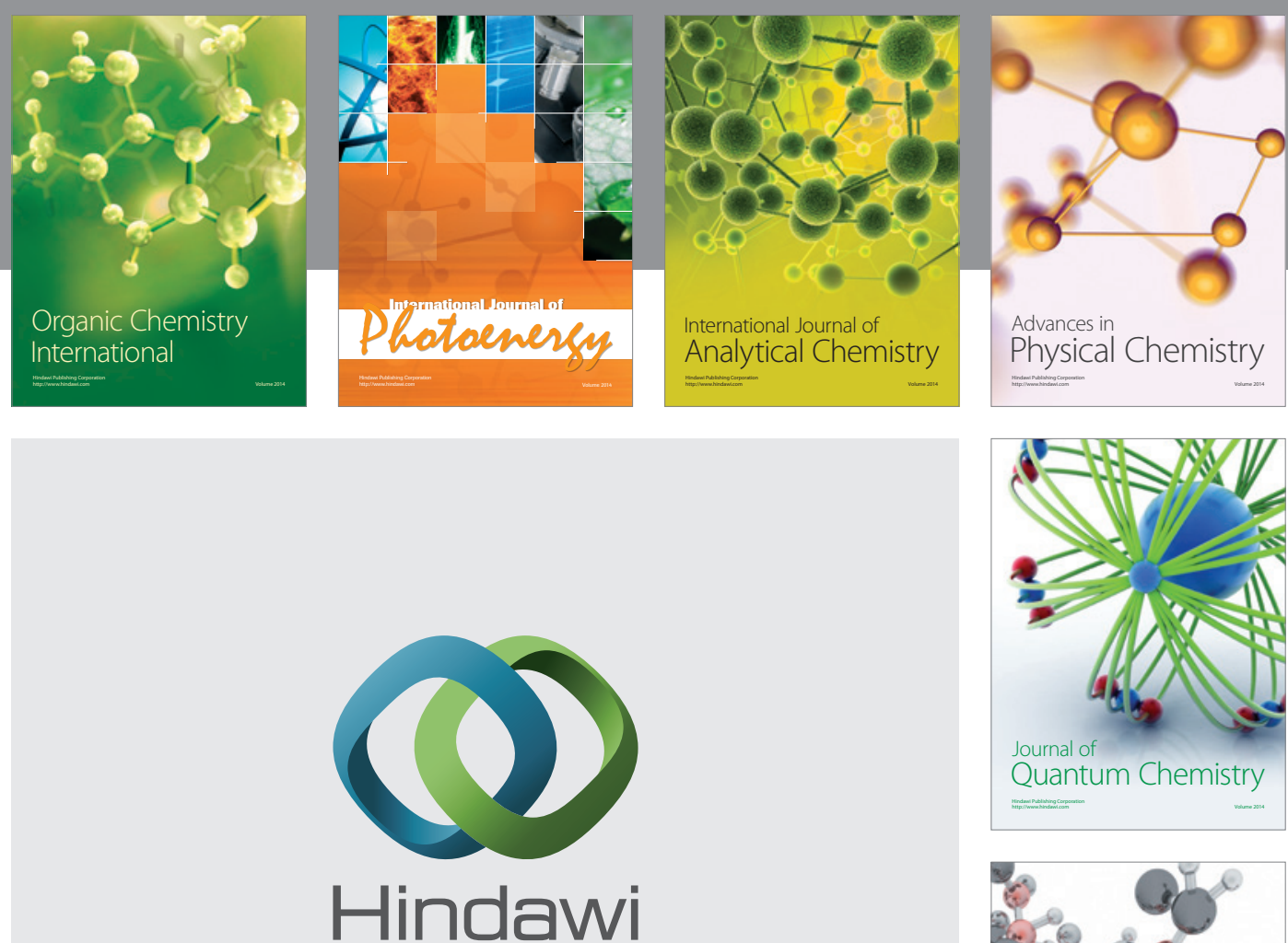

Submit your manuscripts at

http://www.hindawi.com

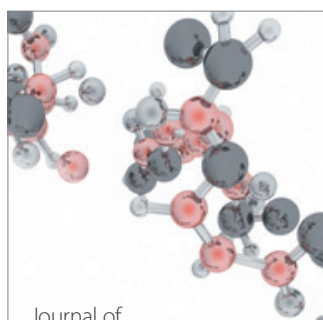

Analytical Methods

in Chemistry

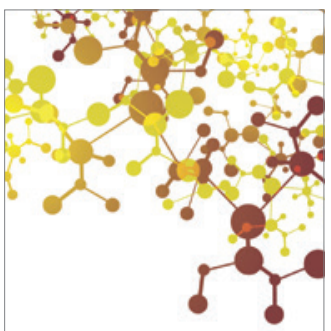

Journal of

Applied Chemistry

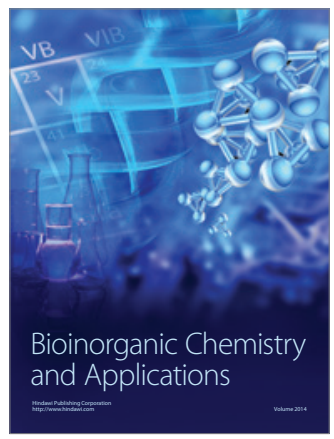

Inorganic Chemistry
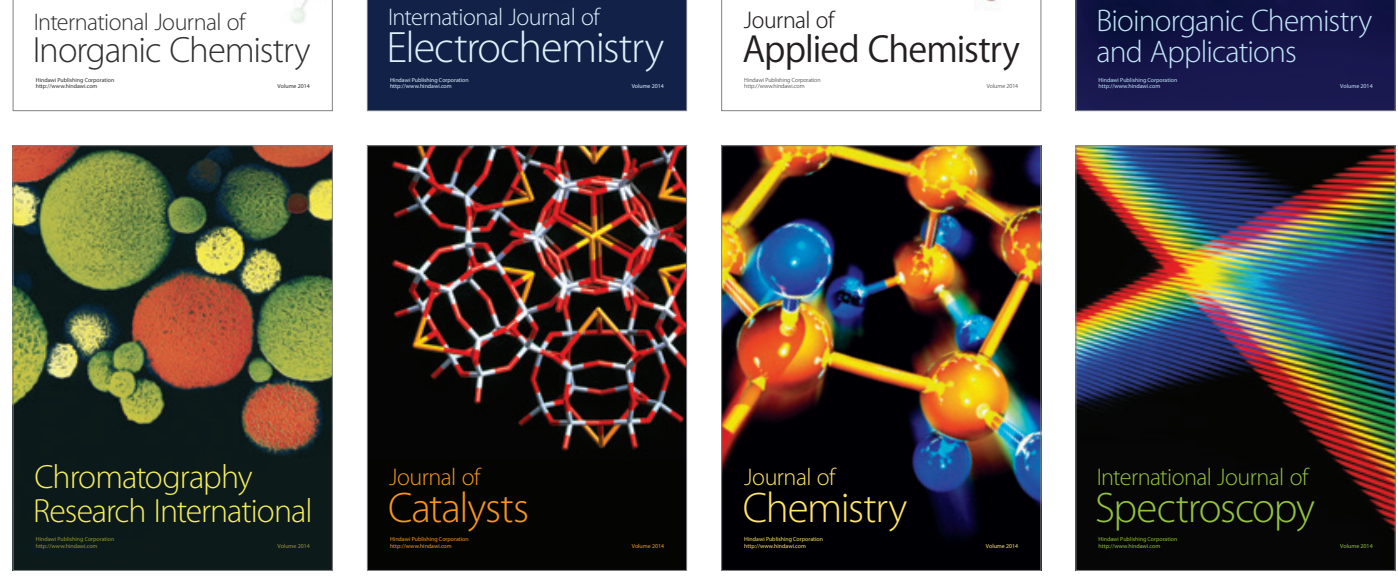